Hiroaki Koh MD, Hironori Ishihara MD, Akemi Miyahara MD, Satoshi Takahashi MD, Akitomo Matsuki MD

\title{
Does the initial distribution volume of glucose reflect plasma volume after haemorrhage in dogs?
}

To test the hypothesis that the initial distribution volume of glucose (IDVG) reflects plasma volume, the relationship between the IDVG and indocyanine green (ICG) assessments of plasma volume (Vd-ICG) were evaluated simultaneously both before and after induced haemorrhage $\left(30 \mathrm{ml} \cdot \mathrm{kg}^{-1}\right)$ in eight mongrel dogs. The IDVG and the Vd-ICG were calculated with a one-compartment model from repeated measurements of plasma glucose three to seven minutes, and of plasma ICG three to nine minutes after simultaneous infusions of both glucose $100 \mathrm{mg} \cdot \mathrm{kg}^{-1}$ and ICG $0.5 \mathrm{mg} \cdot \mathrm{kg}^{-1}$. The IDVG calculated with a one-compartment model (IDVG-OCM) was also compared with a two-compartment model within $15 \mathrm{~min}$ (IDVG-TCM) on nine occasions among a total of 12 determinations. Using Bland and Altman analysis to compare the two analytical models, the IDVG-OCM tends to overestimate the IDVG-TCM by an average of $0.04 \mathrm{~L}$. Although the IDVGOCM was two to three times larger than the Vd-ICG at each corresponding point, a correlation was obtained between the IDVG-OCM and the Vd-ICG before and afier induced haemorrhage ( $r=0.85, n=16, P<0.001$ ). We conclude that the IDVG reflects plasma volume in normal and hypovolaemic dogs, although the IDVG cannot be used directly to estimate plasma volume.

Pour vérifier lhypothèse selon laquelle la distribution initiale du volume de glucose (IDVG) réflète le volume plasmatique,

Key words

BLOOD: plasma;

MEASUREMENT TECHNIQUES: plasma volume; METABOLISM: glucose.

From the Department of Anesthesiology, University of Hirosaki, School of Medicine, Hirosaki-Shi, Aomori-Ken, 036 Japan.

Address correspondence to: Dr. Hironori Ishihara, Department of Anesthesiology, University of Hirosaki School of Medicine, Hirosaki-Shi, Aomori-Ken, 036 Japan.

Accepted for publication 4th October, 1994. la relation entre l'TDVG et l'épreuve de détermination du volume plasmatique (Vd-ICG) par le vert dindocyanine (ICG) est évaluée simultanément avant et après l'hémorragie (30 $\mathrm{ml} \cdot \mathrm{kg}^{-1}$ ) provoquée chez huit chiens de race commune. LIDVG et le Vd-ICG sont calculés sur un modèle à compartiment unique à partir de dosages répétés du glucose plasmatique de trois à sept min, et de l'ICG plasmatique de trois à neuf min, après des perfusions simultanées de glucose 100 $\mathrm{mg} \cdot \mathrm{kg}^{-1}$ et de VTC $0,5 \mathrm{mg} \cdot \mathrm{kg}^{-1}$. LIDVG calculée sur un modèle à compartiment unique (IDVG-OCM) a aussi été comparée en deçà de 15 min à un modèle à deux compartiments (IDVG-TCM) à neuf occasions parmi un total de 12 déterminations. Avec l'analyse de Bland et Altman pour comparer les deux modeles analytiques, I'IDVG-OCM a une tendance à surestimer l'IDVG-TCM par 0,04 L en moyenne. Bien que I'IDVG-OCM soit de deux à trois fois plus considerable que le Vd-ICG à chacun des point correspondants, une corrélation est obtenue entre I'IDVG-OCM et le Vd-ICG avant et après l'hémorragie provoquée ( $r=0,85, n=16, P<0.001$ ). Nous concluons que l'IDVG reflète le volume plasmatique chez les chiens normaux et les chiens hypovolémiques, bien que l'IDVG ne mesure pas directement le volume plasmatique.

Evaluation of fluid volume in the critically ill patient is important when a relatively stable haemodynamic state has been achieved. However, commonly monitored variables, including pulmonary artery wedge pressure, do not always reflect the fluid status adequately.,2 Although the dilution technique using either a radioisotope or a dye has traditionally been used to estimate the volume of body fluid compartments, this method is usually used only in research institutions.

${ }^{14} \mathrm{C}$ labelled glucose has been used as an indicator to measure the extracellular water content. ${ }^{3}$ Recently, we demonstrated that the initial distribution volume of glucose (IDVG) varied markedly among non-surgical critically ill patients, ${ }^{4}$ and modification of glucose kinetics by the insulin response to glycaemic stimuli was negligible during the initial phase of the distribution curve in normal 
and hypovolaemic dogs. ${ }^{5}$ Although the relationship between the IDVG and plasma volume status has not been reported, these results suggest that glucose has potential as an indicator for the measurement of fluid volume.

The purpose of this study is to compare the IDVG and the indocyanine green (ICG) dilution assessment of plasma volume (Vd-ICG) measured simultaneously both before and after induced haemorrhage in dogs.

\section{Methods}

The protocol was approved by the animal investigation committee of the institution. Eight adult mongrel dogs weighing 6.0-10.3 kg were used for the experiments. During pentobarbital anaesthesia $\left(30 \mathrm{mg} \cdot \mathrm{kg}^{-1} i v\right)$, the trachea was intubated and the end-tidal carbon dioxide was maintained at $4.5-5.5 \%$ by mechanical ventilation with room air. The left femoral artery was cannulated for blood sampling and continuous blood pressure monitoring. A pulmonary artery catheter (Baxter Healthcare Corp. Model 93A-741H-7.5F) was inserted through the right femoral vein and advanced until the tip lay in the pulmonary artery. An infusion of lactated Ringer's solution was begun and continued at a rate of $4 \mathrm{ml} \cdot \mathrm{kg}^{-1} \cdot \mathrm{hr}^{-1}$. A period of $30 \mathrm{~min}$ was then allowed to establish a stable circulatory state.

Both $0.5 \mathrm{ml} \cdot \mathrm{kg}^{-1}$ glucose $\left(200 \mathrm{mg} \cdot \mathrm{ml}^{-1}\right)$ and 0.2 $\mathrm{ml} \cdot \mathrm{kg}^{-1}$ ICG $\left(2.5 \mathrm{mg} \cdot \mathrm{ml}^{-1}\right)$ were infused simultaneously through the proximal port of the pulmonary artery catheter over $30 \mathrm{sec}$. Blood samples were drawn immediately before and at 3,5,7, and $9 \mathrm{~min}$ after the injection, respectively. Two hours later, after the infusion, haemorrhage was induced by stepwise bleeding (1 $\mathrm{ml} \cdot \mathrm{kg}^{-1} \cdot \mathrm{min}^{-1}$ ) over $30 \mathrm{~min}$. Thirty minutes after completion of the haemorrhage, three hours after the first infusion, a second series of glucose and ICG infusions, and blood sampling were performed as before the haemorrhage. Additional blood samples were taken up to 30 min postinfusion before and after haemorrhage in six of the eight dogs. All plasma samples were separated immediately and stored at $-20^{\circ} \mathrm{C}$ until measurements of glucose and ICG concentration were completed.

Plasma glucose concentrations were measured using the glucose oxidase method (Gluco-20 glucose analyzer, Fuji Co. Ltd.), and plasma ICG concentrations were measured using a spectrophotometric technique (U3200 Spectrophotometer, Hitachi Co. Ltd.). Each value was measured in duplicate and averaged. Coefficients of variation for repeated measurements were $1 \%$ or less for plasma glucose (range: $3.8-16.7 \mathrm{mmol} \cdot \mathrm{L}^{-1}$ ) and $2 \%$ or less for plasma ICG (range: $0.5-15.0 \mu \mathrm{g} \cdot \mathrm{ml}^{-1}$ ), respectively.

The IDVG for each plasma glucose sample was calculated, using a one-compartment model, from the in- cremental plasma glucose decay curve between three and seven minutes after glucose administration (IDVGOCM). The Vd-ICG was calculated, using a onecompartment model, from the incremental plasma ICG decay curve between three and nine minutes after ICG administration. In a one-compartment model, the volume of distribution (Vd) was calculated as follows: ${ }^{6}$

$\mathrm{Vd}=\operatorname{dose} / \mathrm{C}_{0}$

where dose $=$ amount of drug administered. $\mathrm{C}_{0}=$ initial plasma concentration at time zero after instantaneous distribution, but before the start of elimination. The nine timed plasma glucose values up to $15 \mathrm{~min}$ postinfusion were also fitted to a two-compartment model (IDVGTCM) among a total of 12 determinations for the IDVG before and after haemorrhage. However, the remaining three occasions failed to show a consistent decrease of plasma glucose concentration ten minutes after infusion. Consequently a two-compartment model was not available on those three occasions. In the two-compartment model, the initial volume of distribution (Vd) was calculated as follows:

$\mathrm{Vd}=\operatorname{dose} /(\mathrm{A}+\mathrm{B})$

where $A=$ intercept at time zero of the distribution phase line, $\mathrm{B}=$ intercept at time zero of elimination phase. ${ }^{6}$ The IDVG and the Vd-ICG were determined using a "least squares" regression technique to find the line of best fit. A non-linear multiple regression program "MULTI" was used with the NEC 9800 computer. ${ }^{7,8}$ Akaike's information criterion (AIC) were examined to evaluate exponential term of the pharmacokinetic model. ${ }^{9}$

$\mathrm{AIC}=-2 \log \left(\mathrm{L}_{1}\right)+2 \mathrm{np}$

where $L_{l}$ is the maximum likelihood and np the number of parameters. Convergence was assumed when AIC was less than -10 .

All equipment including the glucose analyzer were calibrated according to manufacturers' recommendations before and after the study. Numerical data are expressed as mean \pm SD. Statistical analysis was performed using Student's $t$ test and regression analysis. Agreement between the two methods was examined by the statistical method described by Bland and Altman. ${ }^{10}$ Values were considered statistically significant when $P<0.05$.

\section{Results}

The AIC for each glucose and ICG regression curve was less than -10.7. The mean AIC was $-23.6 \pm 11.3$ for the IDVG-OCM, $-36.5 \pm 27.3$ for the IDVG-TCM and $-25.9 \pm 5.2$ for the Vd-ICG. The mean plasma glucose concentration before the glucose infusion was $5.3 \pm 2.2$ $\mathrm{mmol} \cdot \mathrm{L}^{-1}$ before haemorrhage and $7.0 \pm 1.3 \mathrm{mmol} \cdot \mathrm{L}^{-1}$ 
TABLE The IDVG and Vd-ICG before and after haemorrhage

\begin{tabular}{lllllll}
\hline & & \multicolumn{2}{l}{$I D V G\left(\mathrm{ml} \cdot \mathrm{kg}^{-1}\right)$} & & \multicolumn{2}{l}{$V d-I C G\left(\mathrm{ml} \cdot \mathrm{kg}^{-1}\right)$} \\
\cline { 3 - 4 } No & $B W(\mathrm{~kg})$ & $B$ & $A$ & & $B$ & $A$ \\
\hline 1 & 7.5 & 130 & 65 & & 47 & 28 \\
2 & 7.5 & 104 & 93 & & 49 & 40 \\
3 & 7.7 & 120 & 82 & & 53 & 35 \\
4 & 8.5 & 101 & 81 & & 44 & 30 \\
5 & 10.1 & 111 & 99 & & 53 & 36 \\
6 & 8.5 & 127 & 74 & & 43 & 27 \\
7 & 6.0 & 123 & 114 & & 61 & 46 \\
8 & 10.3 & 97 & 88 & & 49 & 36 \\
& $8.3 \pm 1.4$ & $114 \pm 13$ & $87 \pm 15 *$ & & $50 \pm 6$ & $35 \pm 6 \dagger$ \\
\hline
\end{tabular}

$\mathrm{B}=$ before haemorrhage, $\mathrm{A}=$ after haemorrhage. IDVG $=$ initial distribution volume of glucose. Vd-ICG $=$ ICG dilution assessments of plasma volume. Values are mean \pm SD. ${ }^{*} P<0.02$ versus $\mathrm{B} . \dagger P<0.001$ versus $\mathrm{B}$.

after haemorrhage. The mean ICG concentration was 7.8 $\pm 0.9 \mu \mathrm{g} \cdot \mathrm{ml}^{-1}$ at three minutes after the ICG infusion before haemorrhage, which consistently decreased to 0.9 $\pm 0.2 \mu \mathrm{g} \cdot \mathrm{ml}^{-1}$ at $30 \mathrm{~min}$ postinfusion before haemorrhage. After haemorrhage the mean incremental plasma ICG concentration above preinfusion value was $10.9 \pm$ $1.8 \mu \mathrm{g} \cdot \mathrm{ml}^{-1}$ at three minutes, which also consistently decreased to $1.0 \pm 0.2 \mu \mathrm{g} \cdot \mathrm{ml}^{-1}$ at $30 \mathrm{~min}$ postinfusion. The plasma ICG concentrations immediately before the second ICG administration were 0.2 and $0.4 \mu \mathrm{g} \cdot \mathrm{ml}^{-1}$ in two dogs among eight dogs. The IDVG-OCM and Vd-ICG in each dog are shown in the Table. The mean IDVG-OCM was $114 \pm 13 \mathrm{ml} \cdot \mathrm{kg}^{-1}$ before haemorrhage, which decreased to $87 \pm 15 \mathrm{ml} \cdot \mathrm{kg}^{-1}$ after haemorrhage. The mean Vd-ICG was reduced from $50 \pm 6$ $\mathrm{ml} \cdot \mathrm{kg}^{-1}$ to $35 \pm 6 \mathrm{ml} \cdot \mathrm{kg}^{-1}$.

A linear correlation was obtained between the IDVGOCM and the Vd-ICG ( $\mathrm{r}=0.85, n=16, P<0.001)$ (Figure 1). The results were similar whether or not body weight corrections were performed.

A correlation was obtained between the IDVG-OCM and the IDVG-TCM ( $\mathrm{r}=0.93, n=9, P<0.001)$. When agreement between the two analytical models was examined, ${ }^{10}$ the one-compartment model was found to overestimate the two-compartment model by an average of $0.04 \mathrm{~L}$. The standard deviation (SD) of the difference between the two models was $0.02 \mathrm{~L}$. Thus, the limits of agreement between the two models were 0.00 to 0.08 L (Figure 2).

\section{Discussion}

The present study demonstrated that a linear correlation existed between the IDVG-OCM and the Vd-ICG, and that the IDVG-OCM correlated well with the IDVGTCM.

Indocyanine green is bound to plasma proteins, dis-

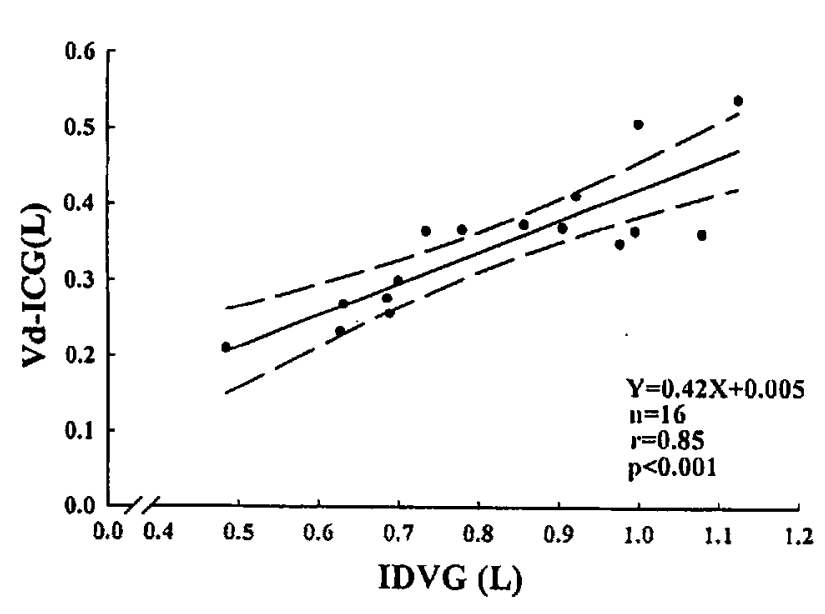

FIGURE 1 The relationship between the initial distribution volume of glucose (IDVG) using a one-compartment model and the distribution volume of indocyanine green (Vd-ICG) in normovolaemic and hypovolaemic dogs. The solid line is a regression line obtained from all data: $\mathrm{Y}=0.42 \mathrm{X}+0.005(\mathrm{r}=0.85, n=16, P<0.001)$.

Dashed lines indicate the $95 \%$ confidence interval for the predicted $\mathrm{Vd}$ ICG for any given value of the IDVG.

tributes throughout the intravascular space, and is cleared by the liver with a high extraction. Thus, ICG has been used for measurements of cardiac output, plasma volume or hepatic blood flow with rare adverse reaction to this drug. ${ }^{11}$ Although the most accurate physiological assessment of the pharmacokinetic behaviour of ICG is thought to be the two-compartment model, ${ }^{12}$ the ICG dilution technique for plasma volume measurements or hepatic blood flow has been traditionally performed by fitting a monoexponential equation to plasma ICG concentration versus time data. ${ }^{13,14}$ In the present study all data were collected three minutes postinfusion to ensure complete mixing within the plasma. ${ }^{15}$ Postequilibration data within 


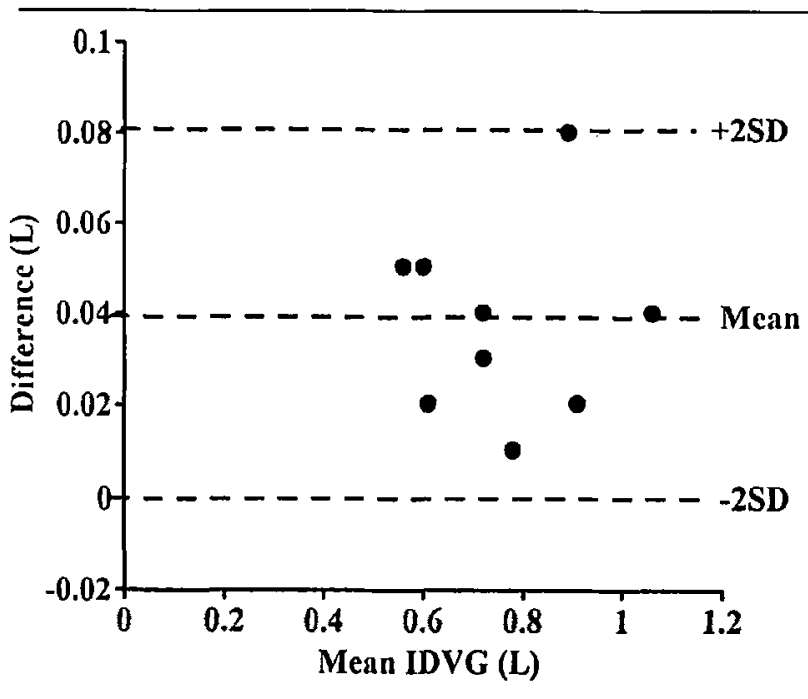

FIGURE 2 Comparison of the difference in the initial distribution volume of glucose (IDVG) derived by a one-(IDVG-OCM) and a twocompartment model (IDVG-TCM) to the mean IDVG obtained with each analytic models. Difference, (IDVG-OCM)-(IDVG-TCM).

the nine minutes were fitted to a one-compartment model as in a previous study. ${ }^{13}$ On the other hand, plasma glucose data were fitted to a one-compartment model within seven minutes postinfusion, because the longer the interval after glucose administration the more would elimination and metabolism modify plasma glucose concentrations. No correlation was reported between the IDVG-OCM and plasma insulin concentrations during and after abdominal hysterectomy, ${ }^{16}$ or before and after haemorrhage in dogs. ${ }^{5} \mathrm{~A}$ good correlation between the IDVG and the Vd-ICG in the present study would also support the hypothesis that modification by glucose metabolism is negligible in the brief time after a glucose administration. However, further study of the IDVG with various blood volume status is required, because the present study dealt with only one change in blood volume. Tracer techniques are also required to evaluate the role of this modification.

Since glucose is already present in the blood, the rate of glucose disappearance from the plasma after a glucose challenge is slowed in accordance with the magnitude of hyperglycaemia before the glucose challenge, ${ }^{17}$ and this may modify the result of the IDVG. Although no dogs in this study had preinfusion plasma glucose $>11$ $\mathrm{mmol} \cdot \mathrm{L}^{-1}$, and no correlation was found between the preinfusion glucose concentration and the slope of the glucose concentration versus time curve $(r=0.28)$, this modification should be taken into account when further studies are required. Multiple doses of ICG may also alter pharmacokinetic disposition. However, this modification would be negligible in this study judged from the observations that plasma ICG concentrations following the first ICG infusion decreased up to $30 \mathrm{~min}$ postinfusion in six dogs, and that ICG was almost cleared from the plasma immediately before the second ICG infusion in two dogs.

The glucose load in this study was much smaller than that of the conventional intravenous glucose tolerance test $\left(>0.3 \mathrm{~g} \cdot \mathrm{kg}^{-1}\right)$. Consequently, plasma glucose concentration ten minutes after the glucose infusion did not always decrease consistently reflecting small fluctuations in glucose metabolism and/or haemodynamic status which would not be obvious during the initial ten minutes. In fact, on three occasions among 16 determinations for the IDVG-TCM in the present study there was no consistent decrease in the plasma glucose ten minutes postinfusion. In addition, with only three samples for each glucose concentration versus time curve, the number of degrees of freedom was insufficient to support more complex models. Considering these factors, we applied a onecompartment model to calculate the IDVG, even though a number of potential inaccuracies are associated with attempting to fit a one-compartment model to the initial phase of a multi-exponential model. Despite a linear correlation between the two-compartment models with a small sampling size in the present study, the IDVG-OCM overestimated the IDVG-TCM by an average of $0.04 \mathrm{~L}$.

Glucose and ICG were infused over $30 \mathrm{sec}$ instead of a single bolus intravenous injection. Since pharmacokinetic variables in this study were derived from the formula based on a single bolus intravenous injection, duration of the infusion may alter results of distribution volumes. Using a mathematical equation proposed by Loo and Riegelman, ${ }^{18}$ the IDVG in this study was found to overestimate values calculated after a single bolus injection by an average of $2.9 \pm 0.9 \%$ for the IDVG and $2.4 \pm 0.4 \%$ for the Vd-ICG, respectively. These above described biases should be taken into account when pharmacokinetic parameters are evaluated more precisely.

Models for glucose distribution and utilization contain at least two glucose pools. One is a "slow" pool which turns over slowly and is insulin-dependent. The other, a "fast" pool, may be divided into plasma and extravascular spaces, and is not insulin-dependent. ${ }^{19}$ The extravascular space consists of the brain, splanchnic organs and kidneys which equilibrate rapidly with plasma glucose. ${ }^{20}$ Using a two-compartment model proposed by Cobelli et al. ${ }^{20}$ the IDVG is $154 \mathrm{ml} \cdot \mathrm{kg}^{-1}$ in healthy volunteers, which is close to the preanaesthetic IDVG in our previous study. ${ }^{16}$ In the present study the IDVG in each dog was found to be two to three times larger than the Vd-ICG. Considering the composition of the fasting pool of glucose, ${ }^{20}$ and the linear correlation between the IDVG and the Vd-ICG, a decrease of the IDVG does 
not reflect total extracellular fluid volume deficits, but may indicate decreases in blood or plasma volume as well as extracellular volume of highly perfused tissues. Since the IDVG can be predicted approximately by only two plasma glucose determinations $(\mathrm{r}=0.94, P<0.001)$ : immediately before glucose is given and three minutes after the challenge, ${ }^{4}$ the IDVG may have potential as an indicator to evaluate the fluid volume status in the body in the operating room or ICU.

In conclusion, the present results demonstrated that changes of the IDVG following acute haemorrhage reflect plasma volume status before and after haemorrhage in dogs, even though the IDVG cannot be used directly to estimate plasma volume.

\section{Acknowledgements}

The authors wish to thank Emeritus Professor J.W.R. McIntyre (Edmonton, Canada) and Professor A.H. Giesecke (Dallas, USA) for their support of this study, and Miss M. Fukuyama for her secretarial help.

\section{References}

1 Shippy CR, Appel PL, Shoemaker WC. Reliability of clinical monitoring to assess blood volume in critically ill patients. Crit Care Med 1984; 12: 107-12.

2 Thys DM, Hillel Z, Goldman ME, Mindich BP, Kaplan $J A$. A comparison of hemodynamic indices derived by invasive monitoring and two-dimensional echocardiography. Anesthesiology 1987; 67: 630-4.

3 Wick $A N$, Drury DR, Mackay EM. Glucose space of the body. Am J Physiol 1950; 163: 224-8.

4 Ishihara H, Shimodate Y, Koh H, Isozaki K, Tsubo T, Matsuki $A$. The initial distribution volume of glucose and cardiac output in the critically ill. Can J Anaesth 1993; 40: 28-31.

5 Shimodate $Y$, Ishihara $H$, Matsuki A. The initial distribution volume of glucose and cardiac output after haemorrhage in dogs. Can J Anaesth 1994; 41: 257-60.

6 Ghoneim $M$, Pearson K. Pharmacokinetics of drugs administered intravenously. In: Scurr C, Feldman S, Soni N (Eds.). Scientific Foundations of Anaesthesia, 4th ed. Chicago: Year Book Medical Publishers, 1990: 559-71.

7 Yamaoka K, Tanigawara Y, Nakagawa T, Uno T. A pharmacokinetic analysis program (MULTI) for microcomputer. Journal of Pharmacobio Dynamics 1981; 4: 879-85.

8 Yamaoka K, Nakagawa T, Tanaka H, Yasuhara $M$, Okumura $K$, Hori $R$. A nonlinear multiple regression program, MULTI 2 (Bayes), based on bayesian algorithm for microcomputers. Journal of Pharmacobio Dynamics 1985; 8: 246-56.

9 Akaike $H$. A new look at the statistical model identification. IEEE Transactions on Automatic Control 1974; AC19: 716-23.
10 Bland JM, Altman DG. Statistical methods for assessing agreement between two methods of clinical measurement. Lancet 1986; 1: 307-10.

11 Benya $R$, Quintana J, Brundage B. Adverse reactions to indocyanine green: a case report and a review of the literature. Cathet Cardiovasc Diagn 1989; 17: 231-3.

12 Avram MJ, Krejcie TC, Henthorn TK. The relationship of age to the pharmacokinetics of early drug distribution: the concurrent disposition of thiopental and indocyanine green. Anesthesiology 1990; 72: 403-11.

13 Haller $M$, Brechtelsbauer $H$, Finsterer $U$, et al. Determination of plasma volume with indocyanine green in humans (German). Anaesthesist 1992; 41: 115-20.

14 Busse MW, Zisowsky S, Henschen B, Panning B, Piepenbrock $S$. Plasma volume estimation using indocyanine green. A single intravenous injection method. Anaesthesia 1993; 48: 41-3.

15 Henthorn TK, Avram MJ, Krejcie TC. Intravascular mixing and drug distribution: the concurrent disposition of thiopental and indocyanine green. Clin Pharmacol Ther 1989; 45: 56-65.

16 Ishihara H, Tanioka $F$, Katagai $H$, et al. Effects of anesthesia and surgery on glucose space in man. Masui 1986; 35: 1057-62.

17 Wolfe RR, Allsop JR, Burke JF. Fallibility of the intravenous glucose tolerance test as a measure of endogenous glucose turnover. Metabolism 1978; 27: 217-26.

18 Loo JCK, Riegelman S. Assessment of pharmacokinetic constants from postinfusion blood curves obtained after iv infusion. J Pharm Sci 1970; 59: 53-5.

19 Cobelli $C$, Bier DM, Ferrannini $E$. Modeling glucose metabolism in man: theory and practice. Horm Metab Res Suppl 1990; 24: 1-10.

20 Cobelli $C$, Toffolo G. A model of glucose kinetics and their control by insulin, compartmental and noncompartmental approaches. Mathematical Bioscience 1984; 72 : 291-315. 